\title{
A Novel Risk Score to Predict New Onset Atrial Fibrillation in Patients Undergoing Isolated Coronary Artery Bypass Grafting
}

\author{
Sophie Z. Lin, PhD, Todd C. Crawford, MD, Alejandro Suarez-Pierre, MD, J. Trent Magruder, MD, \\ Michael V. Carter, Duke E. Cameron, MD, Glenn J. Whitman, MD, Jennifer Lawton, MD, \\ William A. Baumgartner, MD, Kaushik Mandal, MD \\ Division of Cardiac Surgery, Johns Hopkins University School of Medicine, Baltimore, Maryland, USA
}

\section{ABSTRACT}

Background: Atrial fibrillation (AF) is common after cardiac surgery and contributes to increased morbidity and mortality. Our objective was to derive and validate a predictive model for AF after CABG in patients, incorporating novel echocardiographic and laboratory values.

Methods: We retrospectively reviewed patients at our institution without preexisting dysrhythmia who underwent on-pump, isolated CABG from 2011-2015. The primary outcome was new onset $\mathrm{AF}$ lasting $>1$ hour on continuous telemetry or requiring medical treatment. Patients with a preoperative echocardiographic measurement of left atrial diameter were included in a risk model, and were randomly divided into derivation $(80 \%)$ and validation $(20 \%)$ cohorts. The predictors of AF after CABG (PAFAC) score was derived from a multivariable logistic regression model by multiplying the adjusted odds ratios of significant risk factors $(P<.05)$ by a factor of 4 to derive an integer point system.

Results: 1307 patients underwent isolated CABG, including 762/1307 patients with a preoperative left atrial diameter measurement. 209/762 patients (27\%) developed new onset AF including 165/611 (27\%) in the derivation cohort. We identified four risk factors independently associated with postoperative AF which comprised the PAFAC score: age $>60$ years ( 5 points), White race (5 points), baseline GFR $<90 \mathrm{~mL} / \mathrm{min}$ (4 points) and left atrial diameter $>4.5 \mathrm{~cm}$ (4 points). Scores ranged from 0-18. The PAFAC score was then applied to the validation cohort and predicted incidence of AF strongly correlated with observed incidence $(r=0.92)$.

Conclusion: The PAFAC score is easy to calculate and can be used upon ICU admission to reliably identify patients at high risk of developing $\mathrm{AF}$ after isolated CABG.

\section{INTRODUCTION}

Atrial fibrillation (AF) is a common complication after coronary artery bypass grafting $(\mathrm{CABG})$ and reported incidences

Received August 15, 2018; accepted September 28,2018.

Correspondence: Kaushik Mandal, MD, Division of Cardiac Surgery, 1800 Orleans St, Zayed 7107, Baltimore, MD 21287; 410-955-3285; fax: 443287-4226 (e-mail: kmandal2@jbmi.edu). range from 25\%-40\% [Magne 2017; Mathew 2004]. AF increases risk of hemodynamic instability, thromboembolic events such as stroke, and increases overall morbidity and mortality after cardiac surgery [Almassi 1997]. Postoperative $\mathrm{AF}$ has been associated with increased hospital length of stay, increased early stroke risk, and reduced 30-day and long-term survival [El-Chami 2010; Filardo 2009; O’Neal 2013; Villareal 2004]. Identifying important risk factors for the development of postoperative AF will ultimately improve risk stratification and aid in the implementation of perioperative prophylactic interventions.

Many studies have previously elucidated risk factors for postoperative $\mathrm{AF}$, which include older age, previous history of atrial fibrillation, male sex, decreased left ventricular ejection fraction, left atrial enlargement, valve surgery, chronic obstructive pulmonary disease, chronic renal failure, diabetes mellitus, rheumatic heart disease, and obesity [Filardo 2016; Mathew 2004; Melby 2015]. Additionally, several studies have suggested that inflammation contributes to atrial fibrillation. Higher concentrations of inflammatory markers such as C-Reactive Protein (CRP) and Heat Shock Proteins (HSPs; in particular Hsp65 and Hsp70) have been observed in postoperative atrial fibrillation [Afzal 2008; Kinoshita 2011; Mandal 2004; Madal 2005]. Previous studies have not examined the impact of the change in postoperative from preoperative white blood cell (WBC) count on CABG outcomes.

Although multiple risk models have been developed [Amar 2004; El-Chami 2012; Gang 2004; Mariscalco 2014; Mathew 2004; Tran 2015], no single risk score has been adopted to predict $\mathrm{AF}$ after $\mathrm{CABG}$, a reflection of the inherent limitations of databases used in these analyses. The objective of our study was to rexamine risk factors for the development of new onset $\mathrm{AF}$ after isolated $\mathrm{CABG}$, including novel echocardiographic and laboratory variables, and to develop a comprehensive risk score to predict the occurrence of postoperative $\mathrm{AF}$ in patients without a prior history of dysrhythmia.

\section{METHODS}

The Johns Hopkins University Institutional Review Board approved this study and waived the need for individual patient informed consent. 


\section{Patient Selection}

We retrospectively identified all adult patients who underwent on-pump, isolated coronary artery bypass grafting (CABG) from 2011-2015. We excluded patients with a history of dysrhythmia (atrial fibrillation, atrial flutter, supraventricular arrhythmias, etc). We used an institutional Society of Thoracic Surgeons (STS) database to collect demographic data and operative factors. We performed individual reviews of patients' electronic medical records to determine immediate pre- and

Table 1. Characteristics of Patients in Derivation and Validation Cohorts

\begin{tabular}{|c|c|c|c|}
\hline & $\begin{array}{c}\text { Derivation } \\
(\mathrm{n}=611)\end{array}$ & $\begin{array}{c}\text { Validation } \\
(n=151)\end{array}$ & $P$ \\
\hline Age, $n(\%)$ & & & .22 \\
\hline$<60 y$ & $218(36)$ & $62(41)$ & \\
\hline$>60 y$ & $393(64)$ & $89(59)$ & \\
\hline Male sex, n (\%) & $443(73)$ & $114(76)$ & .46 \\
\hline Race, $n(\%)$ & & & .60 \\
\hline White & $426(70)$ & $101(67)$ & \\
\hline African American & $101(17)$ & $26(17)$ & \\
\hline Asian & $19(3.1)$ & $3(2.0)$ & \\
\hline Other & $65(11)$ & $21(14)$ & \\
\hline BMI & $30 \pm 8.9$ & $29 \pm 6.7$ & .26 \\
\hline Baseline eGFR, n (\%) & & & .75 \\
\hline GFR $<90$ & $186(30)$ & $48(32)$ & \\
\hline GFR $>90$ & $425(70)$ & $103(68)$ & \\
\hline Congestive heart failure, $\mathrm{n}(\%)$ & $202(33)$ & $48(32)$ & .77 \\
\hline Coronary disease, $\mathrm{n}(\%)$ & & & .18 \\
\hline 2 vessels & $119(19)$ & $20(13)$ & \\
\hline$\geq 3$ vessels & $444(73)$ & $119(79)$ & \\
\hline Vascular disease, $\mathrm{n}(\%)$ & $59(10)$ & $16(11)$ & .73 \\
\hline Previous myocardial infarction, $\mathrm{n}(\%)$ & $357(58)$ & $87(58)$ & .86 \\
\hline Preexisting lung disease, $\mathrm{n}(\%)$ & & & .48 \\
\hline None & $529(87)$ & $131(87)$ & \\
\hline Mild & $53(8.7)$ & $10(6.6)$ & \\
\hline Moderate/severe & $29(4.7)$ & $10(6.6)$ & \\
\hline Hypertension, n (\%) & $481(79)$ & $123(81)$ & .46 \\
\hline Diabetes, n (\%) & $262(43)$ & $66(44)$ & .87 \\
\hline Operative status, n (\%) & & & .63 \\
\hline Elective & $264(43)$ & $62(41)$ & \\
\hline Urgent/emergent & $347(57)$ & $89(59)$ & \\
\hline CPB time, min & $100 \pm 41$ & $99 \pm 36$ & .62 \\
\hline Cross clamp time, $\min$ & $68 \pm 30$ & $68 \pm 28$ & .93 \\
\hline
\end{tabular}

CPB indicates cardiopulmonary bypass; GFR, glomerular filtration rate. postoperative white blood cell (WBC) count, early exposure to amiodarone (within 6 hours of arrival to ICU), and dosage of inotropes upon arrival to the ICU. Finally, we reviewed preoperative echocardiography (within six months of CABG) and collected data on left atrial diameter. We ultimately excluded patients who only underwent intraoperative, pre-CABG transesophageal echocardiographic assessments, rather than transthoracic echocardiography, and excluded any patient that did not have a recorded measurement of left atrial diameter.

\section{Outcomes}

Our primary outcome of interest was the occurrence of new onset atrial fibrillation/atrial flutter at any time during the postoperative index hospitalization. In accordance with the STS, we defined new onset atrial fibrillation/atrial flutter as any episode lasting longer than one hour and/or requiring treatment. We additionally assessed the association between new onset atrial fibrillation (AF) and the occurrence of stroke, mortality (30 days or during index hospitalization), and postoperative hospital length of stay.

\section{Risk Score Derivation}

We randomly divided our study population into derivation (80\%) and validation (20\%) cohorts. Using a statistical program to generate random quintiles, we assigned four quintiles to the derivation cohort and one quintile to the validation cohort. We then compared demographic and operative data between derivation and validation cohorts and observed no significant variable imbalance (Table 1). Next, we used Lowess smoothing plots to assess for natural inflection points

Table 2. Factors Associated with Development of New-Onset Postoperative Atrial Fibrillation

\begin{tabular}{lcccc}
\hline & & & $95 \%$ & \\
& Odds Ratio & $95 \%$ LL & UL & $P$ \\
\hline Age $>60$ & 2.53 & 1.58 & 4.07 & $<.01$ \\
White race & 2.34 & 1.47 & 3.73 & $<.01$ \\
Hypertension & 1.65 & 0.98 & 2.77 & .06 \\
Preexisting lung disease & & & & \\
Mild & 0.96 & 0.48 & 1.91 & .90 \\
Moderate/severe & 0.20 & 0.06 & 0.72 & .01 \\
GFR $<90$ mL/min & 1.86 & 1.14 & 3.04 & .01 \\
Cardiogenic shock & 0.20 & 0.03 & 1.62 & .13 \\
Preoperative aspirin use & 0.55 & 0.29 & 1.02 & .06 \\
Number of diseased coronaries & & & & \\
$\quad$ Two & 1.28 & 0.49 & 3.38 & .61 \\
$\quad$ Three & 1.01 & 0.41 & 2.48 & .98 \\
Left atrial diameter $>4.5 \mathrm{~cm}$ & 2.00 & 1.19 & 3.36 & .01 \\
\hline
\end{tabular}

GFR indicates glomerular filtration rate. $P$ values in bold are statistically significant. 
relating continuous variables to the occurrence of new onset AF. These inflection points were used to convert continuous variables into categorical variables for the purpose of creating a risk score. We then performed exploratory univariable logistic regression analysis to assess for associations between single variables and our outcome of interest, new onset $\mathrm{AF}$. We tested 32 variables in total that included baseline demographics, preoperative lab and echocardiographic values, preoperative exposure to pharmacologic agents, and postoperative amiodarone and inotrope exposure and ratio of postoperative/preoperative WBC count (Table E1). We defined associations as any variable with an odds ratio $>1$ and a

value $<.2$. Associated covariates were then added manually forward one at a time into a multivariable logistic regression model. Likelihood ratio testing, Akaike Information Criteria, and Hosmer-Lemeshow goodness-of-fit testing were used to construct the most parsimonious multivariable model.

Variables in the multivariable model that were significantly associated with the occurrence of new onset $\mathrm{AF}$ (variables with a $P<.05)$ were used to construct the risk score. Among all significant variables $(P<.05)$, the variable with the lowest odds ratio was used as the baseline variable and adjusted odds ratios were calculated for all remaining significant variables by dividing the lowest significant odds ratio from the absolute odds ratio of each of the remaining significant variables. We then used a multiplier of 4 to convert adjusted odds ratios into scores and we rounded to the nearest whole integer. The summation of these scores comprised the Predictors of Atrial Fibrillation after CABG (PAFAC) score. PAFAC scores were calculated for each study patient and a correlation was drawn between PAFAC scores and the incidence of new onset postoperative atrial fibrillation. The linear regression equation for the line of best fit was then used to predict the occurrence of new onset $\mathrm{AF}$ in the validation cohort.

\section{Risk Score Validation and Stratification}

PAFAC scores were calculated for each patient in the validation cohort. The predicted incidence of new onset $\mathrm{AF}$ was calculated for each unique PAFAC score in the validation cohort and then compared to the observed incidence of AF.

A Lowess smoothing plot was used to relate PAFAC scores in the derivation cohort to the observed incidence of new onset $\mathrm{AF}$ and the natural inflection point in this plot was used to dichotomize patients into low-risk and high-risk groups. Finally, we assessed the risk of stroke, mortality, and prolonged length of stay based on risk stratification of the PAFAC score.

\section{Statistical Analysis}

Descriptive statistics for continuous variables were listed as mean \pm standard deviation for parametric data or median (interquartile range) for non-parametric data and compared using the Student t test or Wilcoxon rank-sum test, respectively. Categorical data were listed as n (\%) and compared using Pearson chi-squared testing. Significance was defined by a $P$ value $<.05$. Variables with $>10 \%$ of patients missing data were excluded from subsequent analyses. STATA 12.0 was used for all statistical analyses (StataCorp, College Station, TX, USA).

\section{RESULTS}

Over the study period, 1307 patients with no history of preoperative dysrhythmia underwent isolated CABG. $762 / 1307$ patients $(58 \%)$ had a preoperative measurement of left atrial diameter. Postoperative WBC counts, amiodarone exposure, and postoperative inotrope dosages were available for all patients. Patients with preoperative left atrial diameter measurements were more often male, had a higher incidence of congestive heart failure (CHF) and previous myocardial infarction (MI), and were more often performed in an urgent/ emergent setting with longer cardiopulmonary bypass times and longer aortic cross-clamp times (Table E2).

Incidence of new onset $\mathrm{AF}$ was $26 \%$ (345/1307 patients) in the overall CABG population and 27\% (209/762) among patients with preoperative measurements of left atrial diameter. Patients who developed postoperative AF were older, more often of white race, and had lower baseline GFR and greater left atrial diameters than their counterparts who convalesced without experiencing AF (Table E3). Among patients that developed postoperative $\mathrm{AF}$, rate of stroke was slightly but insignificantly higher $(3 / 209$ or $1.4 \%$ versus $2 / 553$ or $0.4 \%$; $P=.10)$. Thirty-day mortality was also similar between $\mathrm{AF}$ and non-AF groups $(6 / 209$ or $2.9 \%$ AF versus $9 / 544$ or $1.6 \%$ no AF; $P=.27)$. However, length of stay was significantly

Table 3. Components of the PAFAC Score

\begin{tabular}{|c|c|c|c|c|c|}
\hline Age $>60$ & 2.53 & 1.86 & 1.36 & 4 & 5 \\
\hline $\mathrm{GFR}<90 \mathrm{~mL} / \mathrm{min}$ & 1.86 & 1.86 & 1.00 & 4 & 4 \\
\hline $\begin{array}{l}\text { Left atrial diameter > } \\
4.5 \mathrm{~cm}\end{array}$ & 2.00 & 1.86 & 1.08 & 4 & 4 \\
\hline
\end{tabular}

GFR indicates glomerular filtration rate; PAFAC, predictors of atrial fibrillation after coronary artery bypass grafting. 


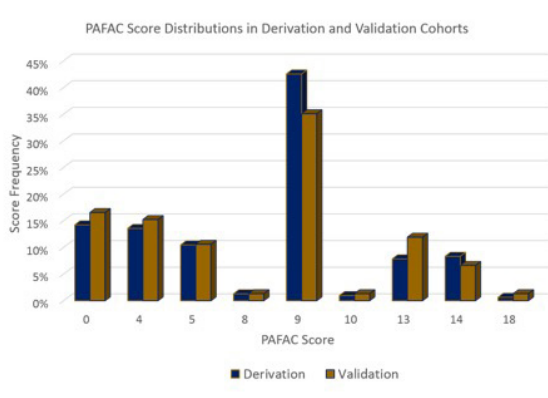

Figure 1. Comparison of Predictors of Atrial Fibrillation after Cardiac Surgery (PAFAC) score distributions in derivation (blue) and validation (gold) cohorts.

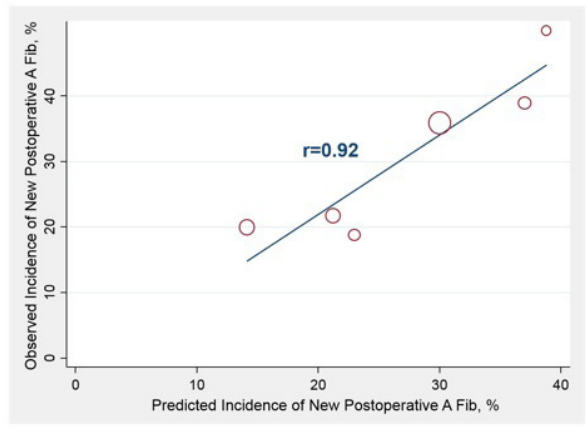

Figure 2. Two-way scatter plot comparing predicted and observed incidences of new onset postoperative atrial fibrillation (AF) for every PAFAC score in the validation cohort. Larger bubble size corresponds to a greater number of patients with a particular PAFAC score. The correlation coefficient, $r=0.92$, from the linear regression equation comparing predicted and observed incidences of new postoperative AF at each unique PAFAC score suggests a strongly positive correlation between predicted and observed incidences.

Table 4. Comparison of High- and Low-Risk Groups Clustered by PAFAC Score

\begin{tabular}{lccc}
\hline & $\begin{array}{c}\text { Low-risk } \\
\text { group }\end{array}$ & $\begin{array}{c}\text { High-risk } \\
\text { group }\end{array}$ & $P$ \\
\hline PAFAC score range & $0-5$ & $8-18$ & \\
Number of patients & 298 & 464 & \\
Incidence of postoperative AF, derivation & $17 \%$ & $33 \%$ & \\
Incidence of postoperative AF, validation & $20 \%$ & $36 \%$ & \\
Overall incidence of postoperative AF, n (\%) & $53(18)$ & $256(34)$ & \\
Operative mortality rate, $\mathrm{n}(\%)$ & $4(1.6)$ & $11(2.2)$ & .32 \\
Incidence of postoperative stroke, $\mathrm{n}(\%)$ & $2(0.7)$ & $3(0.7)$ & .97 \\
Postoperative length of stay, days (median [IQR]) & $6(5-8)$ & $7(6-10)$ & $<.01$ \\
\hline
\end{tabular}

AF indicates atrial fibrillation; IQR, interquartile range; PAFAC, predictors of atrial fibrillation after coronary artery bypass grafting. $P$ values in bold are statistically significant.
Table E1. Exploratory Univariable Analysis

\begin{tabular}{|c|c|c|}
\hline Patient Demographics & $\begin{array}{l}\text { Preoperative Phar- } \\
\text { macologic Exposure }\end{array}$ & $\begin{array}{c}\text { Postoperative } \\
\text { Variables }\end{array}$ \\
\hline Age $>60$ & Statin & $\begin{array}{c}\text { Amiodarone within } \\
6 \text { hours }\end{array}$ \\
\hline Male sex & Corticosteroids & $\begin{array}{l}\text { Highest Epinephrine/ } \\
\text { Norepinephrine } \\
\text { Dose } \geq 0.05 \mathrm{mcg} / \mathrm{kg} / \\
\text { min within first hour }\end{array}$ \\
\hline White race & Inotropes & $\begin{array}{c}\text { Postoperative/Preop- } \\
\text { erative white blood } \\
\text { cell ratio }>2\end{array}$ \\
\hline Hypertension & Beta Blockade & \\
\hline Diabetes & Aspirin & \\
\hline Congestive heart failure & Coumadin & \\
\hline \multicolumn{3}{|l|}{ Peripheral vascular disease } \\
\hline Chronic lung disease & Operative Variables & \\
\hline None & $\begin{array}{c}\text { Number of diseased } \\
\text { coronaries }\end{array}$ & \\
\hline Mild or unknown severity & 1 Vessel & \\
\hline Moderate or severe & 2 Vessels & \\
\hline $\begin{array}{l}\text { Previous myocardial infarc- } \\
\text { tion }\end{array}$ & $\geq 3$ Vessels & \\
\hline Body Mass Index & $\begin{array}{l}\text { Cardiopulmonary } \\
\text { bypass time }\end{array}$ & \\
\hline$\leq 25$ & $\leq 60$ minutes & \\
\hline $26-30$ & $61-200$ minutes & \\
\hline$>30$ & $>200$ minutes & \\
\hline Baseline GFR $<90 \mathrm{~mL} / \mathrm{min}$ & $\begin{array}{l}\text { Aortic cross-clamp } \\
\text { time }\end{array}$ & \\
\hline LV ejection fraction & $\leq 30$ minutes & \\
\hline$>60 \%$ & $31-100$ minutes & \\
\hline $36-60^{\wedge}$ & $>100$ minutes & \\
\hline$\leq 35 \%$ & $\begin{array}{l}\text { Intraoperative blood } \\
\text { transfusion }\end{array}$ & \\
\hline Previous cardiac surgery & $\begin{array}{l}\text { Nadir intraoperative } \\
\text { hematocrit }\end{array}$ & \\
\hline $\begin{array}{l}\text { Cardiogenic shock within } \\
24 \text { hours of operation }\end{array}$ & $\leq 20 \%$ & \\
\hline $\begin{array}{l}\text { Urgent/Emergent opera- } \\
\text { tive status }\end{array}$ & $21-30 \%$ & \\
\hline $\begin{array}{l}\text { Cardiopulmonary resuscita- } \\
\text { tion within } 24 \text { hours of } \\
\text { operation }\end{array}$ & $>30 \%$ & \\
\hline $\begin{array}{l}\text { Left Atrial Diameter > } \\
4.5 \mathrm{~cm}\end{array}$ & $\begin{array}{l}\text { Intraaortic balloon } \\
\text { pump }\end{array}$ & \\
\hline
\end{tabular}

GFR indicates glomerular filtration rate; LV, left ventricle. 
longer. Median length of stay was 8 days (IQR 6-12 days) in patients that developed AF versus 6 days (IQR 5-8 days) in patients who did not experience $\mathrm{AF}$ (rank-sum $P<.01$ ).

\section{PAFAC Score Derivation}

After testing 32 variables individually in the derivation cohort, we identified 16 variables associated with new onset

Table E2. Comparison of CABG Patients with and without Preoperative Measurement of Left Atrial Diameter

\begin{tabular}{|c|c|c|c|}
\hline & $\begin{array}{c}\text { No LA } \\
\text { Diameter } \\
\text { measurement } \\
(n=545)\end{array}$ & $\begin{array}{l}\text { LA Diameter } \\
\text { measure- } \\
\text { ment } \\
(n=762)\end{array}$ & $P$ \\
\hline Age, n (\%) & & & .85 \\
\hline$<60 y$ & $203(37.3)$ & $280(36.8)$ & \\
\hline$>60 y$ & $342(62.8)$ & $482(63.3)$ & \\
\hline Male sex, n (\%) & $431(79.1)$ & $557(73.1)$ & .01 \\
\hline Race, n (\%) & & & .14 \\
\hline White & $403(73.9)$ & $527(69.2)$ & \\
\hline African American & $67(12.3)$ & $194(14.8)$ & \\
\hline Asian & $18(3.3)$ & $40(3.1)$ & \\
\hline Other & $57(10.5)$ & $143(10.9)$ & \\
\hline BMI & $30.0 \pm 6.3$ & $30.0 \pm 8.5$ & 1.00 \\
\hline Baseline eGFR, n (\%) & & & .37 \\
\hline GFR $<90$ & $180(33.0)$ & $234(30.7)$ & \\
\hline GFR $>90$ & $365(67.0)$ & $528(69.3)$ & \\
\hline Congestive heart failure, $\mathrm{n}(\%)$ & $139(25.5)$ & $250(32.8)$ & $<.01$ \\
\hline Coronary disease, n (\%) & & & .78 \\
\hline Single vessel & $32(6.0)$ & $36(4.9)$ & \\
\hline Double vessel & $107(19.9)$ & $139(18.8)$ & \\
\hline Triple vessel & $399(74.2)$ & $563(76.3)$ & \\
\hline Vascular disease, $\mathrm{n}(\%)$ & $38(9.0)$ & $55(10.4)$ & .57 \\
\hline Previous myocardial infarction, $\mathrm{n}(\%)$ & $224(41.1)$ & $444(58.3)$ & $<.01$ \\
\hline Preexisting lung disease, n (\%) & & & .45 \\
\hline Mild & $44(8.1)$ & $63(8.3)$ & \\
\hline Moderate/severe & $20(3.7)$ & $39(5.1)$ & \\
\hline Hypertension, n (\%) & $133(85.8)$ & $112(85.5)$ & .94 \\
\hline Diabetes, n (\%) & $235(43.2)$ & $328(43.1)$ & .97 \\
\hline Operative status, n (\%) & & & $<.01$ \\
\hline Elective & $354(65.0)$ & $326(42.8)$ & \\
\hline Urgent/emergent & $191(35.1)$ & $436(57.2)$ & \\
\hline CPB time & $86.4 \pm 37.4$ & $100.1 \pm 39.8$ & $<.01$ \\
\hline Cross-clamp time & $56.7(24.0)$ & $68.1(29.1)$ & $<.01$ \\
\hline
\end{tabular}

CPB indicates cardiopulmonary bypass; GFR, glomerular filtration rate; LA, left atrium. $P$ values in bold are statistically significant. postoperative $\mathrm{AF}$, including 11 that ultimately comprised the most parsimonious multivariable regression model (Table 2), which included 5 variables that were significantly associated with new onset AF. Moderate/severe preexisting lung disease was protective against new onset AF (OR $0.20,95 \%$ CI $0.06-$ $0.72, P=.01)$, but was not included in the risk score as it did not confer increased risk for AF. This rendered four remaining variables that ultimately comprised the PAFAC score (Table 3). The area under the receiver operating characteristics curve for the PAFAC score was 0.60. Scores ranged from 0 to a maximum of 18 , and nine unique scores were possible. Notably, preoperative statin use, exposure to amiodarone or moderate-to-high dose inotropes, and postoperative to preoperative WBC count ratios were not significantly associated with new onset AF. PAFAC score distributions are pictured in Figure 1. Scores were then plotted against the observed incidence of $\mathrm{AF}$ for each particular score in the derivation cohort and a line of best fit was drawn. The linear regression equation for the line of best was $y=1.7608 x+14.148$.

\section{PAFAC Score Validation}

PAFAC scores were calculated for each of the 151 patients in the validation cohort. The distribution of scores again ranged from 0 to 18 and was similar to the distribution in the derivation cohort (Figure 1). Utilizing the linear regression equation from the line of best fit in the derivation cohort, we were able to calculate a predicted incidence of $\mathrm{AF}$ for each unique score in the validation cohort. Observed incidences of $\mathrm{AF}$ were then measured for each PAFAC score in the validation cohort and compared to predicted incidences in a bubble plot (Figure 2). Larger bubbles correspond to a higher frequency for a particular score. Specific scores with a frequency of $<10 \%$ in derivation and validation populations (scores 8 , 10 , and 18) were excluded when comparing observed versus predicted incidences in order to eliminate potential outliers. Observed incidences of AF correlated positively with predicted incidences of $\mathrm{AF}$ in the validation cohort $(\mathrm{r}=0.92)$.

\section{Risk Score Stratification}

Lowess smoothing plots were used to stratify study patients into low- and high-risk groups. An inflection point in the incidence of $\mathrm{AF}$ was noted at scores $\geq 9$, and patients were therefore dichotomized into low- and high-risk groups depending on whether or not the PAFAC score was $<9$. Incidence of postoperative $\mathrm{AF}$ was two-fold higher in the highrisk group (Table 4). Operative mortality and stroke rates were similar between low-risk and high-risk groups. However, median length of stay was significantly longer in high risk patients ( 7 days versus 6 days, rank sum $P<.01$ ).

\section{DIsCussion}

The PAFAC score is a novel means for predicting new onset atrial fibrillation after CABG in patients without a previous history of dysrhythmia, and takes into account both demographic and morphologic risk factors. A multivariable logistic regression model identified four variables independently associated with new onset $\mathrm{AF}$, which comprised the 
Table E3. Comparison of Patients by Outcome of Interest, New-Onset Postoperative Atrial Fibrillation

\begin{tabular}{|c|c|c|c|}
\hline & $\begin{array}{l}\text { No POAF } \\
(n=553)\end{array}$ & $\begin{array}{c}\text { POAF } \\
(n=209)\end{array}$ & $P$ \\
\hline Age, mean $\pm S D$ & $62 \pm 10$ & $68 \pm 10$ & $<.01$ \\
\hline Male, n (\%) & $408(73.8)$ & $149(71.3)$ & .50 \\
\hline Race, n (\%) & & & $<.01$ \\
\hline White & $363(65.6)$ & $164(78.5)$ & \\
\hline African American & $105(19.0)$ & $22(10.5)$ & \\
\hline Asian & $17(3.1)$ & $5(2.4)$ & \\
\hline Other & $68(12.3)$ & $18(8.6)$ & \\
\hline BMI, mean (SD) & $30 \pm 6.3$ & $30 \pm 13$ & .70 \\
\hline Baseline eGFR & & & $<.01$ \\
\hline Stage $0(>90 \mathrm{~mL} / \mathrm{min})$ & $191(34.5)$ & $43(20.6)$ & \\
\hline Stage $1(61-90 \mathrm{~mL} / \mathrm{min})$ & $208(37.6)$ & $98(46.9)$ & \\
\hline Stage $2(31-60 \mathrm{~mL} / \mathrm{min})$ & $122(22.1)$ & $52(24.9)$ & \\
\hline Stage $3(16-30 \mathrm{~mL} / \mathrm{min})$ & $13(2.4)$ & $7(3.3)$ & \\
\hline Stage $4(<15 \mathrm{~mL} / \mathrm{min})$ & $14(2.5)$ & $8(3.8)$ & \\
\hline Congestive heart failure & $181(32.7)$ & $69(33.0)$ & .99 \\
\hline Coronary disease & & & .40 \\
\hline Single-vessel & $26(4.7)$ & $10(4.8)$ & \\
\hline Double-vessel & 98 (17.7) & $41(19.6)$ & \\
\hline Triple-vessel & $409(74.0)$ & $154(73.7)$ & \\
\hline Peipheral vascular disease & $48(8.7)$ & $27(12.9)$ & .10 \\
\hline Myocardial infarction & $322(58.2)$ & $122(58.4)$ & .99 \\
\hline Preexisting lung disease & $32(5.8)$ & $7(3.3)$ & .40 \\
\hline Hypertension & $427(77.2)$ & 177 (84.7) & .03 \\
\hline Diabetes & $240(43.4)$ & $88(42.1)$ & .80 \\
\hline Left atrial diameter $\pm S D$ & $3.83 \pm 0.66$ & $3.99 \pm 0.69$ & $<.01$ \\
\hline \multicolumn{4}{|l|}{ Preoperative medications, n (\%) } \\
\hline Beta blockers & $492(89.0)$ & $184(88.0)$ & .80 \\
\hline Steroids & $16(2.9)$ & $3(1.4)$ & .40 \\
\hline Inotropes & $11(2.0)$ & $3(1.4)$ & .80 \\
\hline Coumadin & $11(2.0)$ & $1(0.5)$ & .20 \\
\hline Statins & $466(84.3)$ & $173(82.8)$ & .70 \\
\hline Operative status & & & .50 \\
\hline Elective & $232(42.0)$ & $94(45.0)$ & \\
\hline Urgent/emergent & $321(58.0)$ & $115(55.0)$ & \\
\hline Cardiopulmonary bypass time, mean \pm SD & $100 \pm 38$ & $102 \pm 44$ & .50 \\
\hline Cross-clamp time, mean \pm SD & $68 \pm 29$ & $69 \pm 30$ & .70 \\
\hline \multicolumn{4}{|l|}{ Intraoperative characteristics } \\
\hline Nadir hematocrit, mean \pm SD & $25 \pm 4.6$ & $25 \pm 4.6$ & .60 \\
\hline IABP use, $n(\%)$ & $117(21.2)$ & $52(24.9)$ & .30 \\
\hline Blood products given, $\mathrm{n}(\%)$ & $321(58.0)$ & $117(56.0)$ & .70 \\
\hline Postoperative/preoperative WBC count & $2.31 \pm 1.9$ & $2.24 \pm 0.8$ & .50 \\
\hline
\end{tabular}

PAFAC score: age $>60$ years, White race, GFR $<90 \mathrm{~mL} /$ min and LA diameter $>4.5 \mathrm{~cm}$. The maximum potential score was 18 , and we identified a score greater than 5 as a threshold separating patients into low- and high-risk categories. Patients in the high-risk group were almost twice as likely to develop postoperative $\mathrm{AF}$, and this risk was also higher than the observed incidence of $\mathrm{AF}$ at our institution (>27\%).

Several models for predicting new onset postoperative atrial fibrillation in patients after cardiac surgery have been described and several studies deserve mention. El-Chami and colleagues proposed a model to predict new onset $\mathrm{AF}$ in patients undergoing isolated CABG without a previous history of dysrhythmia and found that advanced age, height, weight, and presence of peripheral vascular disease were independent predictors of postoperative AF [El-Chami 2012]. In this study, left atrial size was not included in the prediction model as this variable was not collected by the Society of Thoracic Surgeons database, but the authors identified height and weight as surrogates for left atrial size. Tran et al proposed a predictive score that incorporated age $\geq 65$ years, left atrial dilation, and mitral valve disease to identify patients at risk of developing postoperative AF [Tran 2015]. In this study, left atrial dilation was defined as left atrial size $>41 \mathrm{~mm}$ on the most recent echocardiogram, or described as mild dilation or greater. Finally, in a large European study, Mariscalco et al published the postoperative $\mathrm{AF}$ (POAF) score, a risk index that implicated age, COPD, GFR $<15 \mathrm{~mL} / \mathrm{min}$, emergent surgery, preoperative IABP, $\mathrm{LVEF}<30 \%$, and valve surgery as risk factors for the development of AF after CABG and/ or valve surgery [Mariscalco 2014]. Furthermore, our group previously determined that left atrial diameter was the best predictor for future development of new onset AF following mitral valve repair in patients with isolated degenerative mitral regurgitation, a preserved ejection fraction, and no history of AF [Magruder 2016]. Finally, Borde et al reported an association between higher CHA2DS2-VASc score $(>3)$ and incidence of POAF, but this scoring system does not take into account left atrial size, an important covariate of POAF [Borde 2014].

Our study is one of the first to include left atrial diameter measurements in a risk score for predicting AF after cardiac surgery. Left atrial volume is a known predictor of postoperative AF [Osranek 2006], and a recent study demonstrated a strong correlation between increased left atrial volume and incidence of AF after CABG [Magne 2017], providing further support for the importance of left atrial size as a risk factor in the development of AF. We sought to incorporate this parameter into a risk model using left atrial diameter measurements that were available for patients who underwent CABG at our institution between 2011 and 2015. Our study showed that left atrial diameter $>4.5 \mathrm{~cm}$ was independently associated with increased risk of new onset $\mathrm{AF}$ after isolated CABG.

Previous literature has identified inflammation as an important mediator of AF [da Silva 2017]. While higher preoperative concentrations of inflammatory markers have been associated with increased risk of developing postoperative $\mathrm{AF}$, it remains unclear how the intraoperative inflammatory response to both surgery and cardiopulmonary bypass 
affects postoperative $\mathrm{AF}$. We used postoperative to preoperative WBC count ratio as a surrogate marker of the inflammatory response to cardiac surgery, as it was measured routinely pre- and postoperatively at our institution. Interestingly, and contrary to our expectations, increased ratio of postoperative/ preoperative WBC count was not associated with increased for postoperative $\mathrm{AF}$.

Catecholamines increase sympathetic tone, which has also been implicated in the development of postoperative AF. Elevated postoperative levels of norepinephrine have been associated with increased AF risk [Kalman 1995]. In a metaanalysis of 33 studies, administration of amiodarone, either pre- or postoperatively, was associated with a significant reduction in postoperative AF [Arsenault 2013]. Contrary to our expectations, neither treatment with high dose catecholamines (epinephrine, norepinephrine or dopamine) nor early amiodarone prophylaxis were independently associated with the risk for $\mathrm{AF}$.

There are several notable limitations to our study. First, this was a retrospective single-center study. While we were able to data mine information pertaining to inotrope dosage, amiodarone exposure, and postoperative WBC count, we were still constrained by the limited variables captured in our STS database. Specifically, preoperative mitral regurgitation, postoperative potassium and magnesium nadir were not included in our analyses. Mitral regurgitation (MR) was a rare event in our sample of patients who underwent isolated CABG $(11 \%$, $2 \%$ and $<1 \%$ with mild, moderate, or severe MR respectively), thus we did not include the presence of any degree of $M R$ as a variable in the univariate logistic regression. Second, we had a small sample size, owing to a sizable percentage of isolated CABG patients (42\%) missing preoperative left atrial diameter measurements. There are several possible reasons for this: first, measurements of left atrial diameter are most often obtained during preoperative TTE, which was pursued only in certain settings. For example, patients with preexisting left ventricular dysfunction or STEMI/NSTEMI were more likely to get preoperative LA diameter measurement than those with compensated heart disease. Next, some of the patients who were transferred from outside hospitals where the TTE was performed had unavailable or missing LA diameter measurements. Lastly, many of the patients without a LA diameter measurement had TTE reports that used descriptors such as "normal" or "mild/ moderate/severe LA enlargement" rather than providing a specific measurement, and we felt imputing measurements for LA diameter based on these descriptors would introduce unnecessary bias. Additionally, in constructing a risk model, we were committed to converting continuous variables into categorical variables, resulting in the loss of some statistical validity. Finally, while the PAFAC score tested reliably in our institutional $\mathrm{CABG}$ population, it remains uncertain if the score is applicable to other patient populations.

In conclusion, our single-institution review of patients who underwent isolated CABG identified age $>60$ years, White race, GFR $<90 \mathrm{~mL} / \mathrm{min}$, and left atrial diameter $>4.5$ $\mathrm{cm}$ as independent risk factors associated with new onset AF. The PAFAC scoring system is an easy, convenient, and reliable method to predict new onset $\mathrm{AF}$ and takes into account variables that are readily known at the time of the operation. Knowledge of a patient's PAFAC score will improve risk stratification and enable providers to identify those that may benefit from aggressive pharmacologic measures to prevent AF.

\section{REFERENCES}

Afzal AR, et al. 2008. Association of Met439Thr substitution in heat shock protein 70 gene with postoperative atrial fibrillation and serum HSP70 protein levels. Cardiology 110:45-52

Almassi GH, et al. 1997. Atrial fibrillation after cardiac surgery: a major morbid event? Ann Surg 226:501-11; discussion 511-3.

Amar D, et al. 2004. Clinical prediction rule for atrial fibrillation after coronary artery bypass grafting. J Am Coll Cardiol 44:1248-53.

Arsenault KA, et al. 2013. Interventions for preventing post-operative atrial fibrillation in patients undergoing heart surgery. Whitlock, RP, ed. Cochrane Db Syst Rev 1:CD003611.

Borde D, et al. 2014. Prediction of postoperative atrial fibrillation after coronary artery bypass grafting surgery: is CHA 2 DS 2 -VASc score useful? Ann Cardiac Anaesth17:182-7.

da Silva RMFL. 2017. Influence of inflammation and atherosclerosis in atrial fibrillation. Current Atherosclerosis Reports 19:2 .

El-Chami MF, et al. 2010. New-onset atrial fibrillation predicts longterm mortality after coronary artery bypass graft. J Am Coll Cardiol 55:1370-6.

El-Chami MF, et al. 2012. Prediction of new onset atrial fibrillation after cardiac revascularization surgery. Am J Cardiol 110:649-54.

Filardo G, et al. 2009. New-onset postoperative atrial fibrillation after isolated coronary artery bypass graft surgery and long-term survival. Circ Cardiovasc Qual Outcomes 2:164-9.

Filardo G, et al. 2016. Sex differences in the epidemiology of new-onset in-hospital post-coronary artery bypass graft surgery atrial fibrillation: a large multicenter study. Circ Cardiovasc Qual Outcomes 9:723-30.

Gang Y, et al. 2004. Preoperative electrocardiographic risk assessment of atrial fibrillation after coronary artery bypass grafting. J Cardiovasc Electrophysiol 15:1379-86.

Kalman JM, et al. 1995. Atrial fibrillation after coronary artery bypass grafting is associated with sympathetic activation. Ann Thorac Surg 60:1709-15.

Kinoshita T, et al. 2011. Preoperative C-reactive protein and atrial fibrillation after off-pump coronary bypass surgery. Eur J Cardithorac Surg 40:1298-1303

Magne J, et al. 2017. Echocardiography is useful to predict postoperative atrial fibrillation in patients undergoing isolated coronary bypass surgery: A prospective study. Eur Heart J Acute Cardiovasc Care 17:2048872616688419.

Magruder JT, et al. 2016. Predictors of late-onset atrial fibrillation following isolated mitral valve repairs in patients with preserved ejection fraction. J Cardiac Surg 31:486-92.

Mandal K, et al. 2004. Association of anti-heat shock protein 65 antibodies with development of postoperative atrial fibrillation. Circulation 110:2588-90.

Mandal K, et al. 2005. Association of high intracellular, but not serum, heat shock protein 70 with postoperative atrial fibrillation. Ann Thorac Surg 79:865-71; discussion 871 . 
Mariscalco G, et al. 2014. Bedside tool for predicting the risk of postoperative atrial fibrillation after cardiac surgery: the POAF score. J Am Heart Assoc 3:e000752.

Mathew JP, et al. 2004. A multicenter risk index for atrial fibrillation after cardiac surgery. JAMA 291:1720-9.

Melby SJ, et al. 2015. A time-related parametric risk factor analysis for postoperative atrial fibrillation after heart surgery. J Thorac Cardiovasc Surg 149:886-92.

O'Neal WT, et al. 2013. Impact of race and postoperative atrial fibrillation on long-term survival after coronary artery bypass grafting. J Cardiac Surg 28:484-91.

Osranek M, et al. 2006. Left atrial volume predicts the risk of atrial fibrillation after cardiac surgery: a prospective study. J Am Coll Cardiol 48:779-86

Tran DTT, et al. 2015. Predicting new-onset postoperative atrial fibrillation in cardiac surgery patients. J Cardiothor Vasc An 29:1117-26.

Villareal RP, et al. 2004. Postoperative atrial fibrillation and mortality after coronary artery bypass surgery. J Am Coll Cardiol 43:742-8. 